\title{
Microwave Radiation Impact on Heavy Oil Upgrading from Carbonate Deposits in the Presence of Nano-Sized Magnetite
}

\author{
Alexey V. Vakhin ${ }^{1, *}$, Mohammed A. Khelkhal ${ }^{1, *}$, Arash Tajik ${ }^{1}$, Nikita E. Ignashev ${ }^{1}$, Tatiana O. Krapivnitskaya ${ }^{2}$, \\ Nikolay Yu. Peskov ${ }^{2}$, Mikhail Yu. Glyavin ${ }^{2}$, , Svetlana A. Bulanova ${ }^{2,3}$, Olga V. Slavkina ${ }^{4}$ \\ and Konstantin A. Schekoldin ${ }^{4}$ \\ 1 Institute of Geology and Petroleum Technologies, Kazan Federal University, 18 Kremlyovskaya str., \\ 420008 Kazan, Russia; atajik1989@gmail.com (A.T.); ignashev13nik@mail.ru (N.E.I.) \\ 2 Institute of Applied Physics, Russian Academy of Sciences, 46 Ulyanova St., \\ 603950 Nizhniy Novgorod, Russia; kto465@yandex.ru (T.O.K.); peskov@appl.sci-nnov.ru (N.Y.P.); \\ glyavin@appl.sci-nnov.ru (M.Y.G.); bulanova@ipfran.ru (S.A.B.) \\ 3 Faculty of Chemistry, UNN Campus, Nizhny Novgorod State University N.I. Lobachevsky, \\ 603950 Nizhniy Novgorod, Russia \\ 4 OJSC RITEK, 85 Lesogorskya St., 400048 Volgograd, Russia; olga.slavkina@lukoil.com (O.V.S.); \\ Konstantin.schekoldin@lukoil.com (K.A.S.) \\ * Correspondence: vahin-a_v@mail.ru (A.V.V.); amine.khelkhal@gmail.com (M.A.K.)
}

Citation: Vakhin, A.V.; Khelkhal, M.A.; Tajik, A.; Ignashev, N.E.; Krapivnitskaya, T.O.; Peskov, N.Y.; Glyavin, M.Y.; Bulanova, S.A.; Slavkina, O.V.; Schekoldin, K.A. Microwave Radiation Impact on Heavy Oil Upgrading from Carbonate Deposits in the Presence of Nano-Sized Magnetite. Processes 2021, 9, 2021. https://doi.org/10.3390/ pr9112021

Academic Editor: Amir Tabakovic

Received: 14 October 2021

Accepted: 8 November 2021

Published: 12 November 2021

Publisher's Note: MDPI stays neutral with regard to jurisdictional claims in published maps and institutional affiliations.

Copyright: (c) 2021 by the authors. Licensee MDPI, Basel, Switzerland. This article is an open access article distributed under the terms and conditions of the Creative Commons Attribution (CC BY) license (https:/ / creativecommons.org/licenses/by/ $4.0 /)$.
Abstract: The present paper reports experiments on microwave heating of a carbonate oil-containing rock sample in the presence and absence of an iron-magnetite-based nanocatalyst. It has been shown that the used catalyst improves the processes of destructive hydrogenation of resins and asphaltenes compounds in the oil. The chemical reactions analysis demonstrated a decrease in asphaltenes content and in their molecular weight, which increases the filtration capacity of the oil fluid in the reservoir rock porous medium. Moreover, the content of non-extractable organic matter in the rock sample after experiments and after oil extraction was determined. It has been found that the absence of the catalyst causes the least increase in the content of non-extractable organic matter in the rock. This fact is related to the intensive processes of resinous-asphaltene compounds destruction especially at the level of peripheral groups which are the most condensed fraction, and hence leads to a decrease in their solubility in the organic medium and eases their adsorption on the mineral skeleton surface.

Keywords: microwave radiation; heavy oil; catalyst; magnetite; aquathermolysis; oil content; gas composition

\section{Introduction}

The last decade have witnessed an increase in heavy oil production utilizing thermal enhanced oil recovery methods as an energy efficiency techniques especially in the presence of fundamentally new class of reagents such as in-situ catalysts of aquathermolysis [1-6]. Many previous works and field experiments have demonstrated the effectiveness of such reagents [7-10]. Other works, suggest another way of improving the efficiency of in-situ aquathermolysis catalysts by exposing the reservoir to microwave radiation. In other words, the distributed catalyst particles within the formation may stimulate the reservoir coverage in the presence of microwave radiations [6,11].

Heavy oils reserves in the Russian Federation are estimated to range from 6 to 7 billion tons among which $55 \%$ are unconventional. In fact, heavy oils contain, in addition to resins and asphaltenes, a lot of heteroatoms such sulfur. Russian heavy and extra heavy oil fields are located in the Perm region, Tatarstan, Bashkiria and Udmurtia and their largest fields are presented by Van-Yeganskoe, Severo-Komsomolskoe, Usinskoe, Russkoe, Gremikhinskoe fields and others. It is worthy to note that more than $2 / 3$ of these heavy oil reserves are located at depths of up to $2000 \mathrm{~m}$ and the significant parts are located in dense carbonate rocks [12]. In terms of geological age, about $74 \%$ of these reserves 
belong to the Paleozoic era. Nonetheless, the Mesozoic deposits are characterized by the highest values of oil viscosity meanwhile the lowest viscosity values are observed in the Proterozoic deposits. Moreover, the maximum values of viscosity are characteristic of the transition from one geological era to another. This may be the result of the influence of transgressions and regressions of the world ocean [13].

What we know about iron compounds is largely based on their wide use for catalytic aims whether in a heterogeneous or homogeneous form. Thus, in alkylation reactions, iron compounds (oxides, spinals, zeolites, and molecular sieves) are highly active and can outperform catalysts based on $\mathrm{Al}^{+3}$. A radical cation mechanism of benzylation with the intermediate formation of $\mathrm{Fe}^{2+}$ has been proposed for iron chloride supported on aluminum oxide in the works conducted by Salavati et al. [14].

In recent years, there has considerable interest in catalysts based on $\gamma-\mathrm{Fe}_{2} \mathrm{O}_{3}$ nanoparticles supported on silicas of various structures using a solution of iron acetylacetonate in toluene. These compounds proved to be effective catalysts for a number of chlorolefin conversions, including isomerization of allyl chlorolefins, alkylation of benzene with allyl chloride and benzyl chloride $[15,16]$. In terms of activity and stability, they are in all cases superior to catalysts based on $\alpha-\mathrm{Fe}_{2} \mathrm{O}_{3}$ prepared from the more common precursor, iron nitrate. For example, in benzylation, the most active samples turned out to be samples on an activated silica gel matrix with a high $18 \%$ iron content, which simultaneously contain $\gamma-\mathrm{Fe}_{2} \mathrm{O}_{3}$ and $\mathrm{Fe}_{3} \mathrm{O}_{4}$ nanoparticles with a size of 2-3 nm [17]. Other uses of iron oxides include their wide use as catalysts in the Fischer-Tropsch synthesis, dehydrogenation, alkylation and other processes $[18,19]$. Moreover, nanosized iron oxides, stabilized on silica or in the bulk of polymer matrices, serve as active and selective catalysts for the conversion of halogenated hydrocarbons [20-22]. On another hand, iron oxide catalysts are highly effective in hydrogenation reactions of highly condensed organic matter, such as brown coal [23,24], shales [25], lignin [26] or heavy oil [26,27]. Several authors have shown an increase in the content of light $\mathrm{C}_{10}-\mathrm{C}_{16}$ alkanes in the treated oil composition relatively to high-molecular homologues $\mathrm{C}_{23}-\mathrm{C}_{29}$. In addition, there has been shown a significant decrease in high molecular weight region intensity of the so-called naphthenic hump, reflecting the content of isoalkanes that undergo destruction [28].

Much work on the potential of combining traditional thermal methods and microwave radiation has been carried out because of the promising effect of this application on enhancing heavy oil and bitumen recovery from reservoirs with low thermal conductivity and low permeability [29]. Besides heavy oil and bitumen reservoirs, microwave treatment can be effective as well for shale rocks as reported by El harfi et al. [30]. In general terms, an electric field oscillating at a high frequency promotes the cleavage of chemical bonds such as in petroleum pitch with a high sulfur content. The addition of a catalyst leads to the formation of hydrogen sulfide which can be further utilized for absorbing the microwave field. However, there are several works which demonstrated that the greatest ability to absorb microwave field is characterized by asphaltenes [31,32]. Taken together, the functioning of the catalysts and the effect of microwave radiation provide deep conversion of resins and asphaltenes, a decrease in the produced oil viscosity, and an increase in oil recovery factor. According to conditions totality for the use of catalytic electromagnetic heating mentioned in literature, the criteria for the applicability of the developed technology are summarized in Table 1.

Table 1. EM Heating Technology applicability criteria.

\begin{tabular}{cc}
\hline Reservoir and Fluid Characteristics & Parameters \\
\hline Layer depth, $m$ & up to 2000 \\
Effective oil-saturated thickness, $m$ & from 3 and more \\
Permeability, $\mu \mathrm{m}^{2}$ & any, if less than 0.10, preliminary fracturing is \\
carried out for the injection of catalysts \\
Oil viscosity in reservoir conditions, $m$ Pa.s & more than 500 \\
Density of oil, $\mathrm{kg} / \mathrm{m}^{3}$ & $850-1100$ \\
\hline
\end{tabular}


The use of microwave exposure is possible on any heavy hydrocarbon feedstock containing resinous-asphaltene substances. The limit value of viscosity indicated in the table is set for the entire array of the analyzed sources. In fact, the minimum value of oil viscosity exposed to microwave heating in the presence of catalysts is reported in the works of Taheri et al. [32]. It has been shown that nanodispersed catalysts can perform two functions: On one hand, efficiently absorb a microwave field with the generation of thermal energy and on another one provides chemical conversion of heavy hydrocarbons molecules. Actually, the most effective in terms of their ability to absorb microwave fields are graphite, $\mathrm{FeS}_{2}, \mathrm{Fe}_{3} \mathrm{O}_{4}, \mathrm{Co}_{3} \mathrm{O}_{4}, \mathrm{NiO}_{\mathrm{x}}$ characterized by a resistivity of $10^{-4}-10^{-2} \mathrm{Ohm}$ $\mathrm{m}$ and providing local heating within $1019-1305^{\circ} \mathrm{C}$ at an industrial radiation frequency of $2.45 \mathrm{GHz}$ and a power of 800 watts. Our knowledge of the effect of the dispersion of catalyst particles on the process of converting microwave radiation into thermal energy and the influence of the electric and magnetic components of the electromagnetic field on the process of chemical conversion of hydrocarbons is largely based on very limited data. The aim of the present research was thus to study further this subject by determining the most effective catalysts with the ability to absorb the microwave field. These catalysts have been found to be primarily oxide-sulfide compounds of a number of transition metals such as $\mathrm{Fe}_{3} \mathrm{O}_{4}, \mathrm{NiO}_{\mathrm{x}}, \mathrm{NiS}_{2}, \mathrm{FeS}_{2}$, etc. This work will be devoted for investigating the magnetite effect on microwave absorption. According to the literature data, magnetite has the greatest ability to absorb the microwave field. The resistivity of magnetite is $10^{-4}-10^{-2} \mathrm{Ohm} \cdot \mathrm{m}$. which makes the heating reaches $1258^{\circ} \mathrm{C}$ near the particles [33].

\section{Materials and Methods}

\subsection{Materials}

The object of the present study was samples of an oil-saturated rocks obtained from the Mayorovskoye field of the Volga-Ural oil and gas province with a $3.8 \mathrm{wt}$ \% organic matter content (Figure 1). It is well known that the most oil-saturated reservoir is the B1 carbonate reservoir of the Upper Fransk-Tournaisian oil and gas complex. The reservoir configuration is shown in Figure 1.
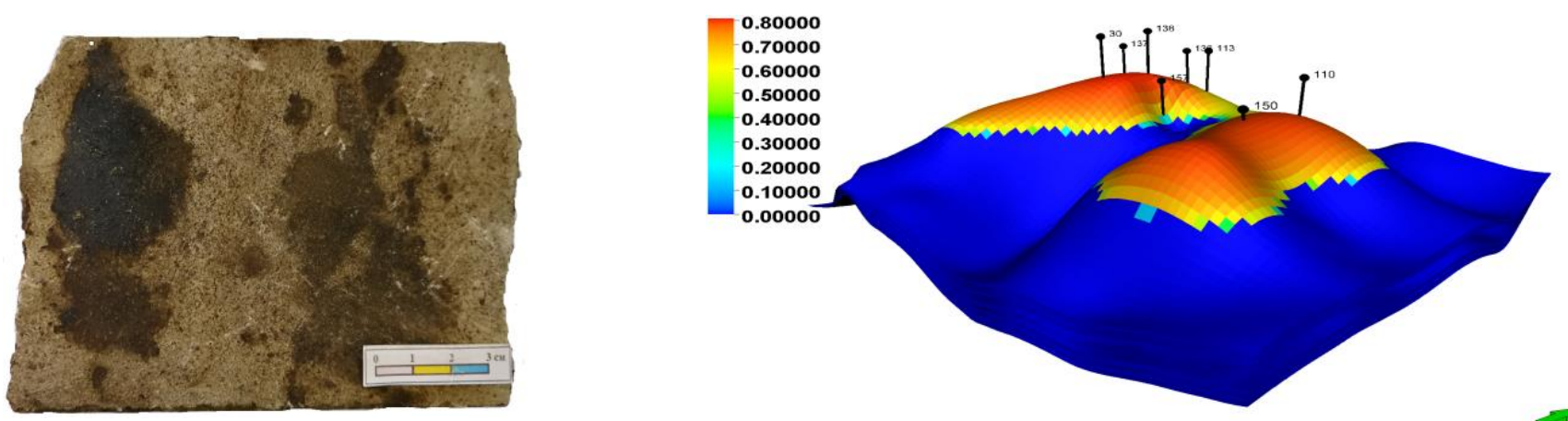

Figure 1. A sample of the Mayorovskoye field oil-saturated rocks and 3D model of oil saturation.

The fractional composition of saturates, aromatic hydrocarbons in addition to resins and asphaltenes contained in the extracted oil from the Mayorovskoye oil-saturated rock has been determined by means of SARA analysis and the obtained data are summarized in Table 2.

Table 2. SARA analysis of the extracted oil from the Mayorovskoye oil-saturated rock.

\begin{tabular}{ccccc}
\hline \multirow{2}{*}{ Sample } & \multicolumn{3}{c}{ SARA Fractions, wt.\% } \\
\cline { 2 - 5 } & Saturates & Aromatics & Resins & Asphaltenes \\
\hline $\begin{array}{c}\text { The extracted oil from the } \\
\text { Mayorovskoye oil-saturated rock }\end{array}$ & 17.2 & 31.4 & 31.3 & 20.1 \\
\hline
\end{tabular}




\subsection{Experiments}

In order to stimulate heavy oil production, we synthesized a nano-sized catalyst based on mixed iron oxide $\mathrm{Fe}_{3} \mathrm{O}_{4}$ at room temperature and atmospheric pressure by mixing two previously prepared aqueous solutions based on the recommendations of Sitnov et al. [34]. The first aqueous solution consisted of a mixture of iron salts $\mathrm{Fe}^{2+}$ and $\mathrm{Fe}^{3+}$ (chlorides, sulfates or nitrates), meanwhile the second aqueous solution consisted of a precipitant. The latter was basic hydroxides, for example ammonium hydroxide, alkaline earth metal hydroxides, and a stabilizing agent, which is used as surfactants (polyacrylic acid, sodium lauryl sulfate). In this case, the mixing process was carried out under continuous cavitation action by means of an ultrasonic disperser for no more than thirty minutes to obtain a sol of mixed iron oxide $\mathrm{Fe}_{3} \mathrm{O}_{4}$. The resulting reaction mass was then treated with ion-exchange resins (cation exchanger-KU-2-8 and anion exchangerAB-17-8) with continuous cavitation effect on the mass, meanwhile ion-exchange resins were added to the reaction mass until the $\mathrm{pH}$ value of the mass reaches a neutral value, to obtain the target product [34].

Four experiments were carried out on a microwave reactor at the Institute of Applied Physics, Russian Academy of Sciences, 46 Ulyanova St., Nizhniy Novgorod, Russia, 603950, under the following conditions presented in Table 3.

Table 3. Microwave reactor experiments conditions.

\begin{tabular}{ccccc}
\hline & $\begin{array}{c}\text { The Presence of } \\
\text { a Catalyst }\end{array}$ & Power, $\mathbf{W}$ & $\begin{array}{c}\text { Exhaust Gas } \\
\text { Temperature, }{ }^{\circ} \mathbf{C}\end{array}$ & Time, min \\
\hline Original rock sample & + & 800 & 110 & 36 \\
Small fraction & - & 600 & 100 & 20 \\
& + & 600 & 110 & 28 \\
\hline
\end{tabular}

The experiment was organized according to the following methodology: the microwave reactor was powered by an industrial $2.46 \mathrm{GHz} / 1 \mathrm{~kW}$ magnetron with a highvoltage power source that allows setting a preset level of output microwave power. The magnetron had additional water cooling for long-term continuous operation of the radiation source. The reactor was a thermally insulated vacuum-tight chamber. The pressure was $0.1 \mathrm{~atm}$. To reduce the reflection coefficient of radiation from the loaded resonatorreactor at an operating frequency of $2.45 \mathrm{GHz}$, the initial installation of the optimal amount of rock sample was carried out. To control the reflected signal during microwave pyrolysis, a directional coupler was included in the path. The initial adjustment of the operating frequency of the resonator was performed using a meter. Reflection does not exceed $-10 \mathrm{~dB}$ in the $2.4-2.54 \mathrm{GHz}$ frequency band. The temperature was measured at the outer boundary of the sample surface using a thermocouple. A rock sample weighing $1 \mathrm{~kg}$ was loaded into a container made of fine metal mesh, which had an air gap from the walls of the reactor to reduce thermal contact with the walls and improve its heating due to gases released during the pyrolysis reaction. The resulting gases were removed from the reactor volume through an outlet valve with a mechanical gate and cooled in a heat exchanger to room temperature. The amount of escaping gas was measured by a gas meter. It allowed to take part of the gas into a special trap for the subsequent study of its chemical composition. Liquid and oily fractions were deposited in primary and secondary fractionation systems. A vacuum pump was used to operate the reactor at a pressure below atmospheric pressure. The time of the experiment varied from 20 to $60 \mathrm{~min}$. The technological block diagram of the experiment is shown in Figure 2. 


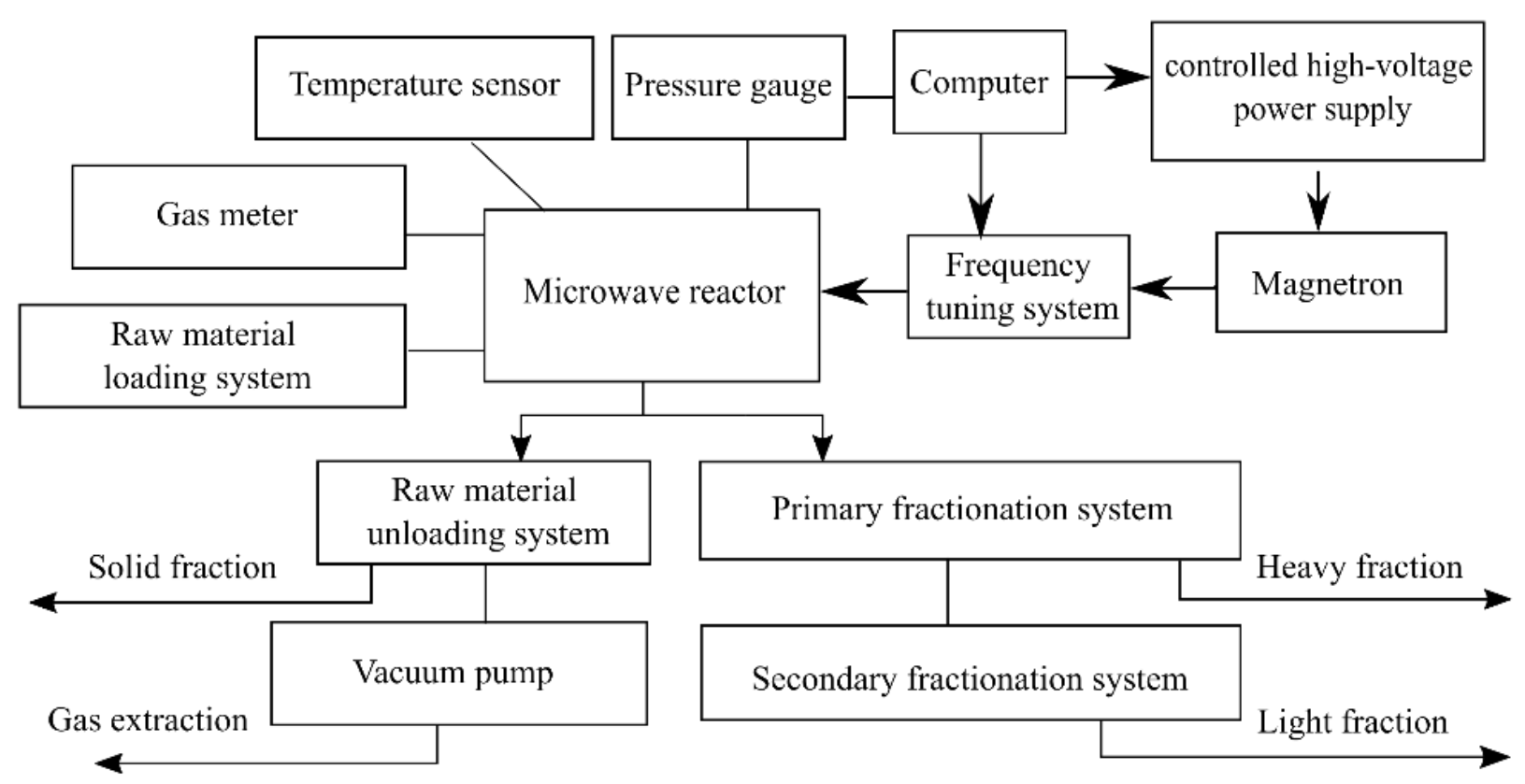

Figure 2. The technological block diagram of the experiment.

SARA Analysis. The group compositions of extracts from the rocks were determined by separating them into four fractions: saturates, aromatics, resins and asphaltenes as per GOST 32269-2013 standard-«Petroleum bitumen. Method of separation into four fractions», which is similar to SARA analysis. Precipitation of asphaltenes was carried out in a 40-fold amount of an aliphatic solvent (hexane). Next, the precipitated asphaltenes were washed off the filter with toluene in a Soxhlet apparatus.

The composition of gases after the experiments were investigated by gas chromatography method in Chromatec-Crystal 5000.2 (Yoshkar-Ola, Mari El Republic, Russina Federation, 2021) with further digital data processing using GOST 32507-2013 (ASTM D 5134-98 (2008), MOD). The gas samples were delivered to the given machine from the autoclave's gas output through special heat resistant tubing. The gas separation was carried out in capillary column with a length of $100 \mathrm{~m}$ and two absorption chambers. Chromatography was run in following temperature mode: from $35^{\circ} \mathrm{C}$ to $250{ }^{\circ} \mathrm{C}$ with the heating rate of $2{ }^{\circ} \mathrm{C} / \mathrm{min}$. The gas carrier was helium and the stream velocity was $25 \mathrm{~mL} / \mathrm{min}$.

Thermal analysis. Organic matter content in rock sample and thermal effects analysis were performed using a synchronous thermal analysis instrument STA 443 F3 Jupiter (Netzsch, Gebrüder-Netzsch-Straße, Selb, Germany) in air as oxidizing environment at a heating rate of $10^{\circ} \mathrm{C} / \mathrm{min}$, and a temperature range of 20 to $1000^{\circ} \mathrm{C}$. TG-DTA curves were processed by means of Netzsch ProteusThermalAnalysis standard software.

\section{Results and discussion}

The composition of non-hydrocarbon gases is shown in Table 4. In all four experiments, oxygen, nitrogen, and carbon dioxide were identified. It has been found that the presence of a magnetite catalyst leads to a significant increase in oxygen content. Moreover, the highest carbon dioxide content was observed in the longest experiment (No 4).

In addition, carbon monoxide and hydrogen were not recorded in all experiments. It is worthy to note that carbon dioxide was the predominant component in gas products. However, the results showed no correlation in the content of carbon dioxide from the conditions of microwave exposure and the presence of a catalyst. In the presence of catalyst in experiments No 1 and No 3, gases of the methane series $C_{5}$ and higher prevailed, among which - propane, n-butane, i-butane, n-pentane, i-pentane, etc have presented the significant amount. Besides, the methane content was several times higher in experiments No 1 and No 3 in the presence of catalyst compared to the non-catalytic experiment. What's 
more, the content of ethane and ethylene naturally increased in a series of experiments No 1 and No 3 as the radiation power decreases. From another hand, the presence of the catalyst leads to significant increasing in the content of pentane molecules. In contrast, the content of butane molecules practically was independent of experimental conditions meanwhile the propane content was at maximum in the experiment without catalyst and it has been found that the largest amount of saturated hydrocarbon gases is formed in the experiment No 3 in the presence of the catalyst.

Table 4. Composition of gas products obtained during experiments.

\begin{tabular}{|c|c|c|c|c|c|c|c|c|c|c|c|c|c|c|c|}
\hline & \multirow[b]{3}{*}{$0^{N}$} & \multicolumn{14}{|c|}{ Hydrocarbon Gases, wt. $\%$} \\
\hline & & \multicolumn{8}{|c|}{ Limit Hydrocarbon Gases } & \multicolumn{5}{|c|}{ Unsaturated Hydrocarbon Gases } & \multirow[b]{2}{*}{$\begin{array}{l}\text { Other } \\
\text { Gases }\end{array}$} \\
\hline & & 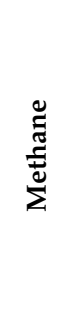 & $\underset{\text { 売 }}{\stackrel{\Xi}{\Xi}}$ & 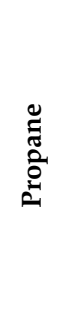 & 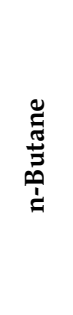 & $\begin{array}{l}\stackrel{0}{\Xi} \\
\stackrel{\Xi}{\Xi} \\
.1\end{array}$ & 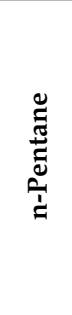 & 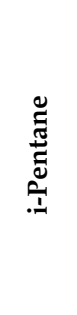 & 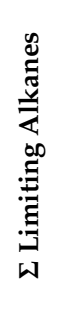 & $\underset{\text { 辛 }}{\stackrel{\Xi}{\Xi}}$ & 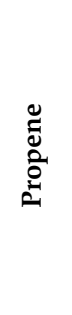 & 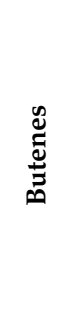 & 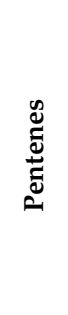 & 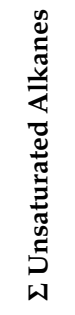 & \\
\hline 1 & 97.4 & 0.46 & 0.04 & 0.08 & 0.16 & 0.04 & 0.15 & 0.12 & 1.05 & 0.01 & 0.05 & 0.15 & 0.12 & 0.34 & 1.26 \\
\hline 2 & 98.1 & 0.10 & 0.16 & 0.27 & 0.08 & 0.05 & 0.03 & 0.02 & 0.72 & 0.18 & 0.19 & 0.17 & 0.06 & 0.60 & 0.55 \\
\hline 3 & 94.2 & 0.22 & 0.30 & 0.12 & 0.07 & 0.06 & 0.04 & 3.75 & 4.56 & 0.25 & 0.19 & 0.17 & 0.07 & 0.69 & 0.58 \\
\hline 4 & 98.5 & 0.07 & 0.27 & 0.11 & 0.06 & 0.01 & 0.03 & 0.01 & 0.58 & 0.17 & 0.20 & 0.18 & 0.08 & 0.63 & 0.31 \\
\hline
\end{tabular}

The oil containing rock extracts have been analyzed after experiments of microwave exposure, and the obtained SARA group analysis has been presented in (Table 5).

Table 5. SARA analysis of the rock extract before and after microwave exposure.

\begin{tabular}{|c|c|c|c|c|c|}
\hline \multirow{2}{*}{\multicolumn{2}{|c|}{ Sample }} & \multicolumn{4}{|c|}{ SARA Fractions, wt. $\%$} \\
\hline & & Saturated HC & Aromatic HC & Resins & Asphaltenes \\
\hline \multicolumn{2}{|c|}{ Original extract } & 17.2 & 31.4 & 31.3 & 20.1 \\
\hline \multirow{4}{*}{$\begin{array}{c}\text { After } \\
\text { microwave } \\
\text { processing }\end{array}$} & No 1 & 19.3 & 20.4 & 39.7 & 20.6 \\
\hline & No 2 & 19.0 & 22.3 & 31.3 & 27.4 \\
\hline & No 3 & 20.1 & 19.3 & 43.3 & 17.3 \\
\hline & No 4 & 19.4 & 17.0 & 44.4 & 19.2 \\
\hline
\end{tabular}

The original composition of oil is characterized by a high content of resinous-asphaltene substances (more than $50 \mathrm{wt} . \%$ ) and a low content of saturated hydrocarbons (17.2 wt.\%). In all scenarios of microwave processing, an increase in the content of saturated hydrocarbons by $2 \mathrm{wt} . \%$ or more is achieved. At the same time, the content of aromatic hydrocarbons decreases in all cases, but to varying degrees. To the greatest extent, the content of aromatic hydrocarbons was observed for the longest experiment (No. 4) —up to $17.0 \mathrm{wt} . \%$. Our data indicate that the lightest fractions have been removed from the rock sample as a result of microwave energy conversion into thermal energy which led to an increase in the content of heavy components. What's more, the obtained results showed a decrease in the content of asphaltenes by 1.3-1.6 times in all experiments with catalysts (No2). This has been provided with a commensurate increase in the content of resins. It should be noted that the ratios of saturates to aromatics is 1.14 for catalytic process. This result is more effective than other alternative noncatalytic methods [35].

The obtained data indicate the occurrence of the destructive hydrogenation process at the carbon-heteroatom bonds in the asphaltene structure. In this case, a part of the aromatic hydrocarbon fraction can act as a hydrogen donor with a corresponding decrease in solubility and their transfer to the resin fraction. The result of a variety of chemical reactions is a decrease in the content of asphaltenes and a decrease in their molecular 
weight, which increases the filtration capacity of the oil fluid in the porous medium of the reservoir rock. Previously, filtration experiments were carried out for such catalysts [9]. this effect can be explained by the destruction of asphaltene aggregates and a decrease in their molecular weight [36]. As a result, the rheological parameters of the oil change [37].

A wide range of literature has reported that oil yield increases in the presence of iron or nickel oxides nanoparticles as a result of asphaltenes destruction $[38,39]$.

In order to determine the content of non-extractable organic matter in the composition of the oil-containing rock and the effect of the microwave field in the presence of catalyst on the possible additional generation of coke-like substances like carbene-carboids (compaction products during asphaltene conversion reactions), thermogravimetric study of rock samples after oil extraction was carried out. Weight loss during thermal analysis of the extracted rock samples is presented in Table 6 and the obtained general thermograms are presented by Figures 3 and 4 .

Table 6. Weight loss during thermal analysis of the extracted rock samples before and after microwave exposure.

\begin{tabular}{|c|c|c|c|c|c|c|c|c|}
\hline \multirow{2}{*}{\multicolumn{2}{|c|}{ Sample }} & \multicolumn{6}{|c|}{ Temperature Ranges, ${ }^{\circ} \mathrm{C}$} & \multirow{2}{*}{ Total Weight Loss } \\
\hline & & Up to 100 & $100-200$ & $200-300$ & $300-400$ & $400-500$ & $500-600$ & \\
\hline \multicolumn{2}{|c|}{ Original Extract } & 0.33 & 0.30 & 0.44 & 1.17 & 0.65 & 0.86 & 3.75 \\
\hline \multirow{4}{*}{$\begin{array}{c}\text { After } \\
\text { microwave } \\
\text { processing }\end{array}$} & No 1 & 0.40 & 0.29 & 0.40 & 0.66 & 0.80 & 1.45 & 4.00 \\
\hline & No 2 & 0.20 & 0.22 & 0.39 & 0.71 & 0.69 & 1.08 & 3.29 \\
\hline & No 3 & 0.12 & 0.56 & 0.69 & 1.52 & 0.72 & 1.79 & 5.40 \\
\hline & No 4 & 0.17 & 0.27 & 0.46 & 0.70 & 0.77 & 1.98 & 4.35 \\
\hline
\end{tabular}

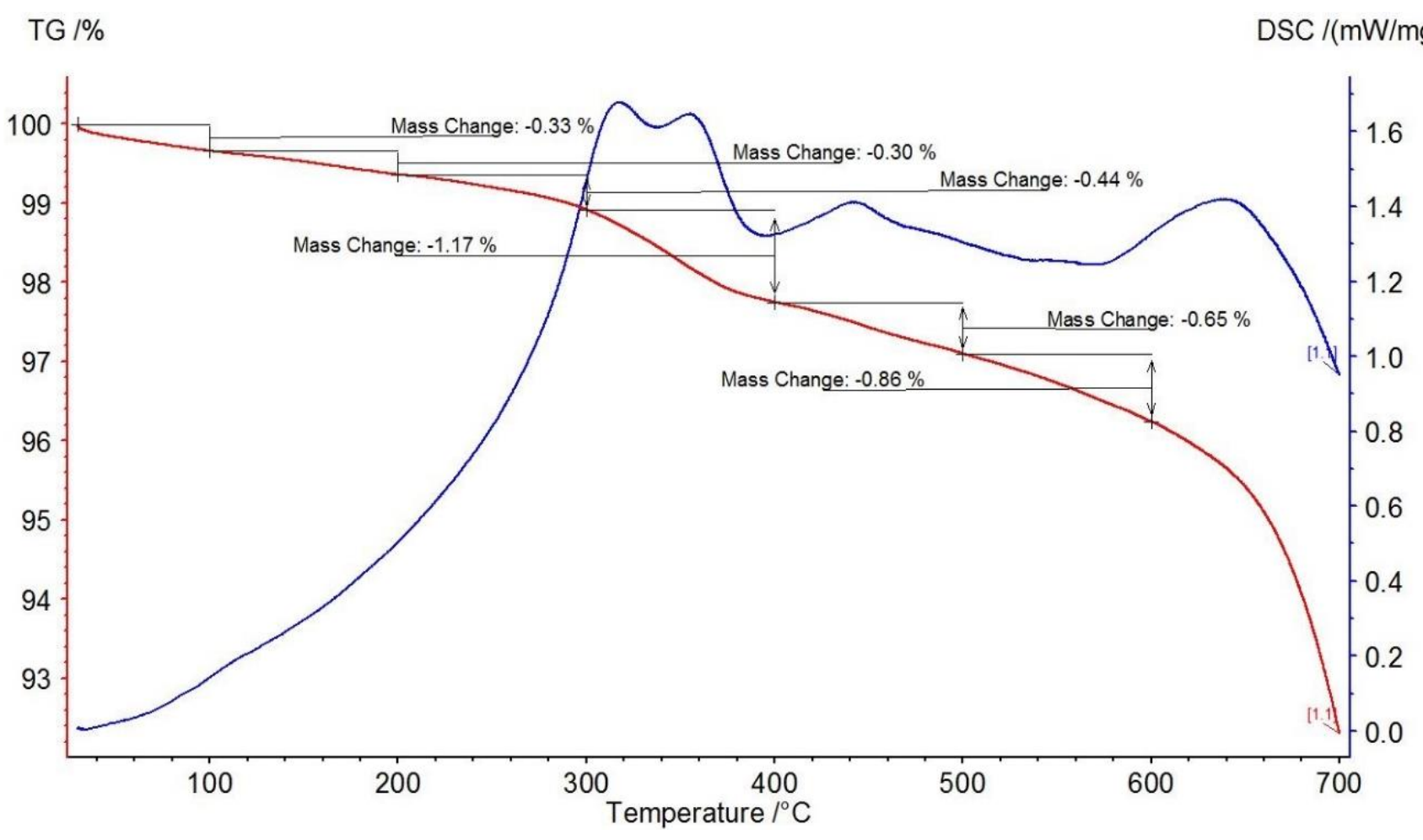

Figure 3. Thermogravimetric analysis of the original rock sample. 

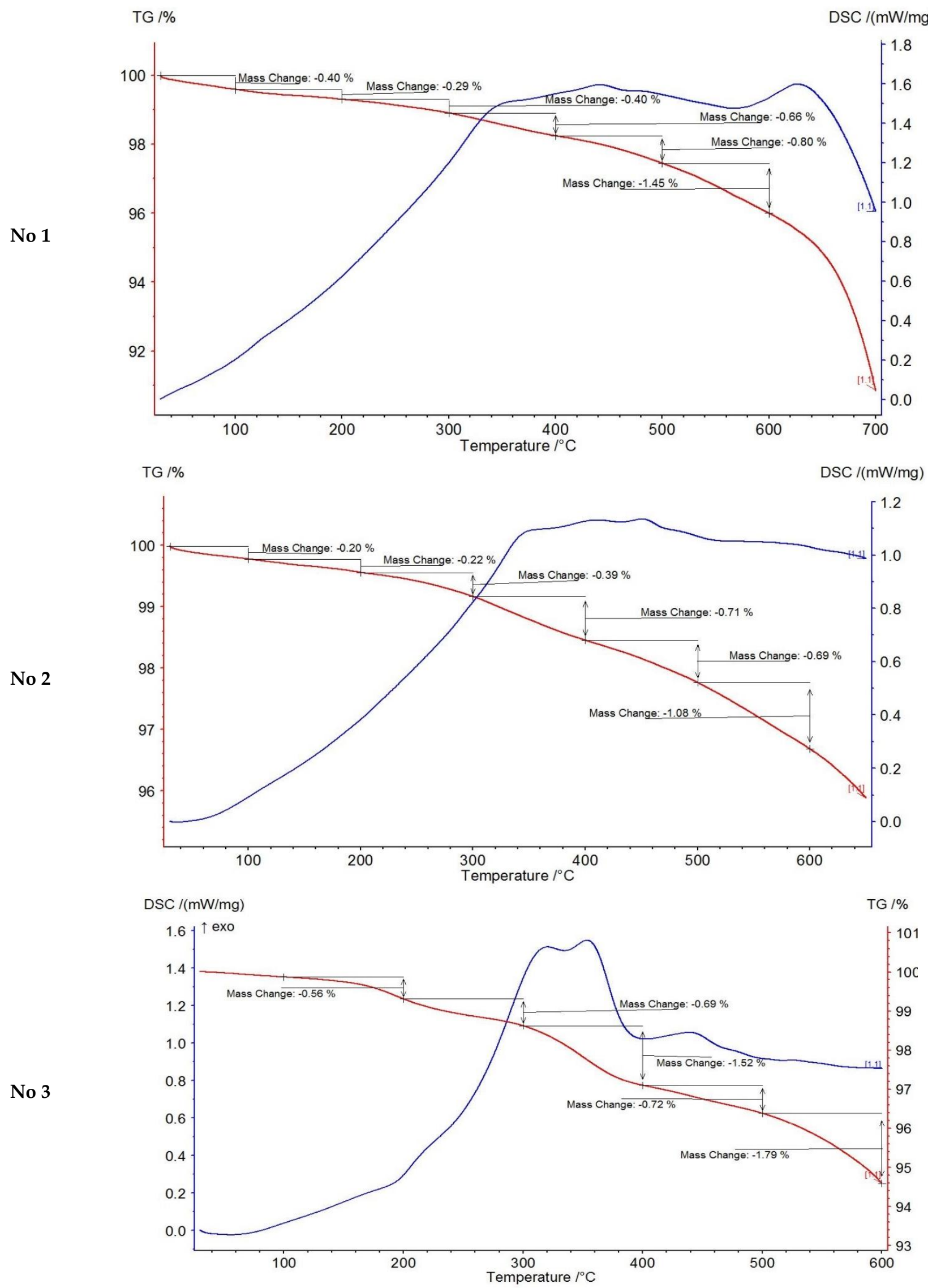

Figure 4. Cont . 


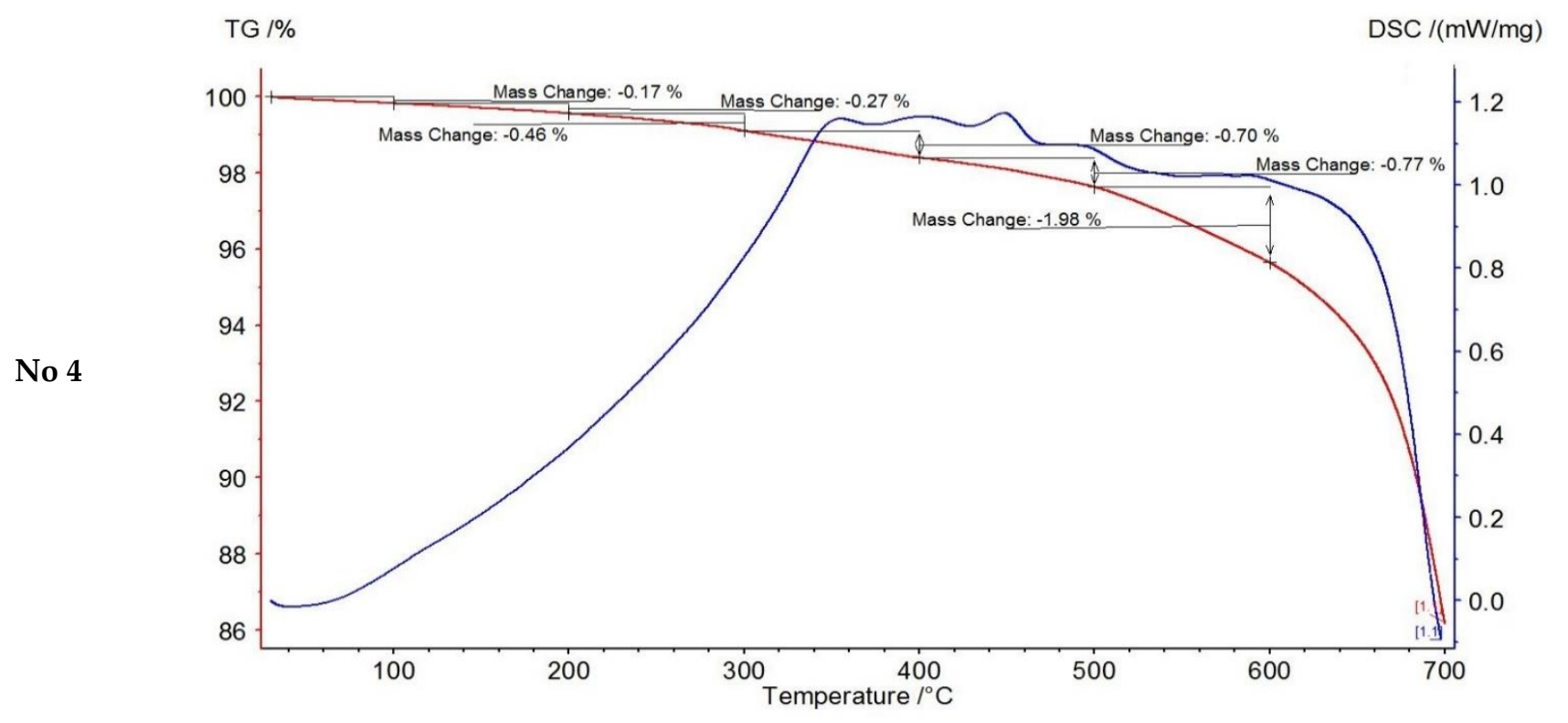

Figure 4. Thermogravimetric analysis of the extracted rock samples after experiments.

It has been found that the absence of the catalyst causes the least increase in the content of non-extractable organic matter in the rock. This fact is related to the intensive processes of resinous-asphaltene compounds destruction especially at the level of peripheral groups which are the most condensed fraction, and hence leads to a decrease in their solubility in the organic medium and eases their adsorption on the mineral skeleton surface.

\section{Conclusions}

A series of experiments was carried out on a sample of oil-containing rock under various modes of microwave exposure in the presence and absence of nanoscale magnetite. The advantage of this laboratory design (with a small amount of substance loaded) was the ability to quickly reach the temperature necessary for the pyrolysis reaction at a relatively low power level. It should be noted that a feature of the experimental setup used was a significant inhomogeneity of the microwave field in the reactor volume, leading to inhomogeneity of heating inside the reactor volume. In order to ensure more uniform heating, it is necessary to optimize the electrodynamic input system of the reactor radiation from the point of view of reducing the reflected power from the study object. The composition of gaseous products of oil transformation in the composition of the rock has been studied in addition to identifying oxygen, nitrogen, and carbon dioxide in all four experiments. It has been found that oxygen content increases noticeably in the presence of magnetite catalyst and the highest carbon dioxide content has been observed in the longest experiment. Moreover, the methane content was found to be several times higher in the presence of catalyst compared with the experiment in its absence. On the other hand, the content of ethane and ethylene naturally increases in a number of experiments as the radiation power decreases. The largest amount of saturated hydrocarbon gases was found to be formed in the experiment with a catalyst.

The group composition of the extracted oil was studied after the experiments, and it has been found that the original composition of oil is characterized by a high content of resinous-asphaltene substances-more than $50 \mathrm{wt}$ \% $\%$ and a low content of saturated hydrocarbons-17.2 wt.\%. In all scenarios of microwave processing, an increase in the content of saturated hydrocarbons by $2 \mathrm{wt} . \%$ or more is achieved. At the same time, the content of aromatic hydrocarbons decreases in all cases, but to varying degrees. It has been shown that the content of aromatic hydrocarbons to a greatest extent, was associated with the longest experiment-up to $17.0 \mathrm{wt} . \%$. As a result of the conversion of microwave energy into thermal energy, the lightest fractions were removed from the rock sample and the content of heavy components increased. What's more, the obtained results showed a 
decrease in the content of asphaltenes by 1.3-1.6 times in all experiments with catalysts (No 2). This has been provided with a commensurate increase in the content of resins. The obtained data indicate the occurrence of the destructive hydrogenation process at the carbon-heteroatom bonds in the asphaltene structure. In this case, a part of the aromatic hydrocarbon fraction can act as a hydrogen donor with a corresponding decrease in solubility and their transfer to the resin fraction. The result of a variety of chemical reactions is a decrease in the content of asphaltenes and a decrease in their molecular weight, which increases the filtration capacity of the oil fluid in the porous medium of the reservoir rock.

The content of non-extractable organic matter in the rock sample after experiments and after oil extraction was determined. It has been found that the absence of the catalyst causes the least increase in the content of non-extractable organic matter in the rock. This fact is related to the intensive processes of resinous-asphaltene compounds destruction especially at the level of peripheral groups which are the most condensed fraction, and hence leads to a decrease in their solubility in the organic medium and eases their adsorption on the mineral skeleton surface.

Author Contributions: Conceptualization, M.A.K. and A.V.V.; methodology, M.A.K. and A.V.V.; software, M.A.K.; validation, O.V.S., S.A.B. and K.A.S.; formal analysis, N.E.I. and A.T.; investigation, N.E.I. and M.Y.G.; resources, A.V.V.; data curation, M.A.K.; writing—original draft preparation, A.V.V. and M.A.K.; writing-review and editing, M.A.K.; visualization, T.O.K. and N.Y.P.; supervision, A.V.V.; project administration, A.V.V.; funding acquisition, A.V.V. All authors have read and agreed to the published version of the manuscript.

Funding: This work was supported by the Ministry of Science and Higher Education of the Russian Federation under agreement No. 075-15-2020-931 within the framework of the development program for a world-class Research Center "Efficient development of the global liquid hydrocarbon reserves.

Institutional Review Board Statement: Not applicable.

Informed Consent Statement: Not applicable.

Conflicts of Interest: The authors declare no conflict of interest.

\section{References}

1. Muraza, O.; Galadima, A. Aquathermolysis of Heavy Oil: A Review and Perspective on Catalyst Development. Fuel 2015, 157, 219-231. [CrossRef]

2. Maity, S.K.; Ancheyta, J.; Marroquín, G. Catalytic Aquathermolysis Used for Viscosity Reduction of Heavy Crude Oils: A Review. Energy and Fuels 2010, 24, 2809-2816. [CrossRef]

3. Vakhin, A.V.; Aliev, F.A.; Mukhamatdinov, I.I.; Sitnov, S.A.; Kudryashov, S.I.; Afanasiev, I.S.; Petrashov, O.V.; Nurgaliev, D.K. Extra-Heavy Oil Aquathermolysis Using Nickel-Based Catalyst: Some Aspects of In-Situ Transformation of Catalyst Precursor. Catalysts 2021, 11, 189. [CrossRef]

4. Khelkhal, M.A.; Eskin, A.A.; Nurgaliev, D.K.; Vakhin, A.V. Thermal Study on Stabilizing Combustion Front via Bimetallic Mn@Cu Tallates during Heavy Oil Oxidation. Energy Fuels 2019, 34, 5121-5127. [CrossRef]

5. Khelkhal, M.A.; Eskin, A.A.; Vakhin, A.V. Kinetic Study on Heavy Oil Oxidation by Copper Tallates. Energy Fuels 2019, 33, 12690-12695. [CrossRef]

6. Vakhin, A.V.; Khelkhal, M.A.; Tajik, A.; Gafurov, M.R.; Morozov, O.G.; Nasybullin, A.R.; Karandashov, S.A.; Ponomarev, A.A.; Krapivnitskaia, T.O.; Glyavin, M.Y. The Role of Nanodispersed Catalysts in Microwave Application during the Development of Unconventional Hydrocarbon Reserves: A Review of Potential Applications. Processes 2021, 9, 420. [CrossRef]

7. Farhadian, A.; Khelkhal, M.A.; Tajik, A.; Lapuk, S.E.; Rezaeisadat, M.; Eskin, A.A.; Rodionov, N.O.; Vakhin, A.V. Effect of Ligand Structure on the Kinetics of Heavy Oil Oxidation: Toward Biobased Oil-Soluble Catalytic Systems for Enhanced Oil Recovery. Ind. Eng. Chem. Res. 2021, 60, 14713-14727. [CrossRef]

8. Mukhamatdinov, I.I.; Sitnov, S.A.; Slavkina, O.V.; Bugaev, K.A.; Laikov, A.V.; Vakhin, A.V. The Aquathermolysis of Heavy Oil from Riphean-Vendian Complex with Iron-Based Catalyst: FT-IR Spectroscopy Data. Pet. Sci. Technol. 2019, 37, 1410-1416. [CrossRef]

9. Minkhanov, I.F.; Bolotov, A.V.; Al-Muntaser, A.A.; Mukhamatdinov, I.I.; Vakhin, A.V.; Varfolomeev, M.A.; Slavkina, O.V.; Shchekoldin, K.A.; Darishchev, V.I. Experimental Study on the Improving the Efficiency of Oil Displacement by Co-Using of the Steam-Solvent Catalyst (Russian). Neft. Khozyaystvo-Oil Ind. 2021, 2021, 54-57. [CrossRef] 
10. Kudryashov, S.I.; Afanasiev, I.S.; Petrashov, O.V.; Vakhin, A.V.; Sitnov, S.A.; Akhmadiayrov, A.A.; Varfolomeev, M.A.; Nurgaliev, D.K. Catalytic Heavy Oil Upgrading by Steam Injection with Using of Transition Metals Catalysts (Russian). Neft. Khozyaystvo-Oil Ind. 2017, 2017, 30-34. [CrossRef]

11. Li, H.; Gao, H.; Zhao, X.; Xia, Z.; Yu, B.; Sun, D. Experimental Study on Viscosity Reduction of Heavy Oil with Water Content by Synergistic Effect of Microwave and Nano-Catalyst. J. Pet. Sci. Eng. 2022, 208, 109271. [CrossRef]

12. Muslimov, R.K. On a New Paradigm for the Development of the Oil and Gas Complex in Russia (Russian). Neft. Khozyaystvo-Oil Ind. 2021, 2021, 8-13. [CrossRef]

13. Yashchenko, I.G.; Polishchuk, Y.M. Classification of Poorly Recoverable Oils and Analyis of Their Quality Characteristics. Chem. Technol. Fuels Oils 2016, 52, 434-444. [CrossRef]

14. Vernaya, O.I.; Krotova, I.N.; Maksimov, Y.V.; Rostovshchikova, T.N. Effect of the Support Nature on the Catalytic Properties of Iron in Benzene Benzylation. Pet. Chem. 2017, 57, 93-99. [CrossRef]

15. Tsodikov, M.V.; Rostovshchikova, T.N.; Smirnov, V.V.; Kiseleva, O.I.; Maksimov, Y.V.; Suzdalev, I.P.; Ikorskii, V.N. Structure and Size Effects in Catalysis by Immobilized Nanoclusters of Iron Oxides. Catal. Today 2005, 105, 634-640. [CrossRef]

16. Maksimov, Y.V.; Rostovshchikova, T.N.; Kiseleva, O.I.; Smirnov, V.V.; Suzdalev, I.P.; Prusakov, V.E.; Tsodikov, M.V.; Ikorsky, V.N. Catalytic Conversions of Chloro-Olefins on Iron Oxide Nanoparticles. 3. Electronic and Magnetic Properties of $\mathrm{Fe}_{2} \mathrm{O}_{3}$ Nanoparticles on Silicas of Various Nature. Izv. RAN Phys. Ser. 2010, 74, 328-332.

17. Rostovshchikova, T.; Smirnov, V.; Kiseleva, O.; Yushcenko, V.; Tzodikov, M.; Maksimov, Y.; Suzdalev, I.; Kustov, L.; Tkachenko, O. Acidic and Catalytic Properties of Silica Modified by Iron Oxide Nanoparticles. Catal. Today 2010, 152, 48-53. [CrossRef]

18. Hayashi, H.; Chen, L.Z.; Tago, T.; Kishida, M.; Wakabayashi, K. Catalytic Properties of Fe/SiO2 Catalysts Prepared Using Microemulsion for CO Hydrogenation. Appl. Catal. A Gen. 2002, 231, 81-89. [CrossRef]

19. Kuhrs, C.; Arita, Y.; Weiss, W.; Ranke, W.; Schlögl, R. Understanding Heterogeneous Catalysis on an Atomic Scale: A Combined Surface Science and Reactivity Investigation for the Dehydrogenation of Ethylbenzene over Iron Oxide Catalysts. Top. Catal. 2000, 14, 111-123. [CrossRef]

20. Rostovshchikova, T.N.; Smirnov, V.V.; Tsodikov, M.V.; Bukhtenko, O.V.; Maksimov, Y.V.; Kiseleva, O.I.; Pankratov, D.A. Catalytic Conversions of Chloro-Olefins on Iron Oxide Nanoparticles. Communication I. Isomerization of Dichlorobutenes in the Presence of Iron Oxide Nanoparticles Immobilized on Silicas of Various Structures. Bull. USSR Acad. Sci. Chem. Ser. 2005, 6, $1376-1382$.

21. Rostovshchikova, T.N.; Kiseleva, O.I.; Yurkov, G.Y.; Gubin, S.P.; Pankratov, D.A.; Perfiliev, Y.D.; Smirnov, V.V.; Chernavsky, P.A.; Pankina, G.V. Catalysis of Reactions of Chlorine Olefins of Allyl Structure by Nanosized Iron Oxides. Mosc. Univ. Bull. Epis. 2 Chem. 2001, 42, 318-324.

22. Sitnov, S.; Mukhamatdinov, I.; Aliev, F.; Khelkhal, M.A.; Slavkina, O.; Bugaev, K. Heavy Oil Aquathermolysis in the Presence of Rock-Forming Minerals and Iron Oxide (II, III) Nanoparticles. Pet. Sci. Technol. 2020, 38, 574-579. [CrossRef]

23. Kuznetsov, B.N. Catalysis of Chemical Transformations of Coal and Biomass. Science 1990, 52, 485-492.

24. Derbyshire, F.; Hager, T. Coal Liquefaction and Catalysis. Fuel 1994, 73, 1087-1092. [CrossRef]

25. Taheri-Shakib, J.; Kantzas, A. A Comprehensive Review of Microwave Application on the Oil Shale: Prospects for Shale Oil Production. Fuel 2021, 305, 121519. [CrossRef]

26. Arapova, O.V.; Chistyakov, A.V.; Palankoev, T.A.; Bondarenko, G.N.; Tsodikov, M.V. Microwave-Assisted Lignin Conversion to Liquid Products in the Presence of Iron and Nickel. Pet. Chem. 2020, 60, 1019-1025. [CrossRef]

27. Shang, H.; Yue, Y.; Zhang, J.; Wang, J.; Shi, Q.; Zhang, W.; Liu, L.; Omar, S. Effect of Microwave Irradiation on the Viscosity of Crude Oil: A View at the Molecular Level. Fuel Process. Technol. 2018, 170, 44-52. [CrossRef]

28. Goryachikh, D.V.; Kayukova, G.P.; Nigmedzyanova, L.Z.; Kiyamova, A.M.; Yu, M. Ganeeva Influence of Microwave Heating on the Yield and Composition of Natural Bitumen from Sandstones of the Shugurovskoye Field. Enhanced Oil Recovery at the Late Stage of Oil Field Development and Integrated Development of High-Viscosity Oils and Natur. In Proceedings of the International Scientific and Practical Conference, Moscow, Russia, 1-3 November 2007; pp. 178-183.

29. Leite, L.F.; Borschiver, S.; Canongia, C.; Antunes, A.M.S. Survey of Microwave Technology Potential Application in Heavy Crude Oil Upgrading. In Proceedings of the 2nd Mercosur Congress on Chemical Engineering and 4th Mercosur Congress on Process Systems Engineering, Rio de Janeiro, Brazil, 14-18 August 2005.

30. Mokhlisse, A.; Chanâa, M.B.; Outzourhit, A. Pyrolysis of the Moroccan (Tarfaya) Oil Shales under Microwave Irradiation. Fuel 2000, 79, 733-742.

31. Wong, G.K.; Yen, T.F. An Electron Spin Resonance Probe Method for the Understanding of Petroleum Asphaltene Macrostructure. J. Pet. Sci. Eng. 2000, 28, 55-64. [CrossRef]

32. Li, Y.; Shang, H.; Zhang, Q.; Elabyouki, M.; Zhang, W. Theoretical Study of the Structure and Properties of Ni/V Porphyrins under Microwave Electric Field: A DFT Study. Fuel 2020, 278, 118305. [CrossRef]

33. Vanetsev, A.S.; Tretyakov, Y.D. Microwave-Assisted Synthesis of Individual and Multicomponent Oxides. Russ. Chem. Rev. 2007, 76, 397. [CrossRef]

34. Sitnov, S.A.; Mukhamatdinov, I.I.; Vakhin, A.V.; Katnov, V.E.; Nurgaliev, D.K.; Lyabipov, M.R.; Amerkhanov, M.I. A Method of Producing a Nanosized Catalyst Based on Mixed Iron Oxide for Intensification of the Production of Heavy Hydrocarbon Feedstocks and a Catalyst Obtained by This Method. Patent No. 2655391 RU, 3 December 2018.

35. Ma, W.; Luo, X.; Tao, S.; Liu, J.; Guan, P. Modified Pyrolysis Experiments and Indexes to Re-Evaluate Petroleum Expulsion Efficiency and Productive Potential of the Chang 7 Shale, Ordos Basin, China. J. Pet. Sci. Eng. 2020, 186, 106710. [CrossRef] 
36. Mullins, O.C.; Betancourt, S.S.; Cribbs, M.E.; Dubost, F.X.; Creek, J.L.; Andrews, A.B.; Venkataramanan, L. The Colloidal Structure of Crude Oil and the Structure of Oil Reservoirs. Energy Fuels 2007, 21, 2785-2794. [CrossRef]

37. Matveenko, V.N.; Kirsanov, E.A. The Viscosity and Structure of Dispersed Systems. Mosc. Univ. Chem. Bull. 2011, 66, 199-228. [CrossRef]

38. Bera, A.; Babadagli, T. Effect of Native and Injected Nano-Particles on the Efficiency of Heavy Oil Recovery by Radio Frequency Electromagnetic Heating. J. Pet. Sci. Eng. 2017, 153, 244-256. [CrossRef]

39. Greff, J.; Babadagli, T. Use of Nano-Metal Particles as Catalyst under Electromagnetic Heating for in-Situ Heavy Oil Recovery. J. Pet. Sci. Eng. 2013, 112, 258-265. [CrossRef] 